\title{
DECISÃO E INFORMAÇÃO NA INDÚSTRIA
}

\author{
Ralph Santos da SILVA ${ }^{1}$
}

\begin{abstract}
RESUMO
Ultimamente, tem sido dado mais importância ao T da TI (Tecnologia da Informação) do que ao I. Tal fato pode ser confirmado pelos diversos meios de comunicação que divulgam que a indústria ainda não conseguiu alcançar os resultados esperados que justificaram o investimento em TI. Esta realidade faz-nos refletir sobre a necessidade de estruturar um quadro que forneça as variáveis que possibilitem a reversão desta situação. A proposta deste artigo é construir um contexto que resgata a utilização da informação, de forma efetiva, no processo de decisão da indústria. Identifica a natureza do processo decisório, articula a informação como sua matéria-prima e amplia o próprio ambiente informacional colocando-o numa perspectiva ecológica, isto é, promove a eliminação de contornos que vêm condicionando a informação à perspectiva da engenharia de sistemas. E reconhece a diversidade que representa o mundo da informação.
\end{abstract}

Palavras-chave: tecnologia da informação; tomada de decisão; industria.

\begin{abstract}
Recently, T (Technology) in IT has been receiving more importance than I (Information). This can be confirmed by the several communication media which confirm that indusry has not yet reached the expected results. This reality points out towards the necessity to build a profile that explains the nature of information, to face the situation. This article aims to build such a profile, exploring the old concepts of enterprise and decision process, as well as organizing information to support decisions, under an ecological view. This procedure eliminates constraints imposed from software engineering concepts, and creates appropriate conditions to incorporate the diversity that defines the world of information.
\end{abstract}

Key words: information technology; decision making; industry.

\section{INTRODUÇÃO}

A informação tem sido considerada como o principal elemento de criação de vantagem competitiva. Este fato tem justificado, por si, investimentos em infra-estrutura e ferramentas diversas que propiciam o seu tratamento.
Todavia, a cada dia novas evidências surgem, caracterizando verdadeiros fracassos em termos de competitividade por empresas que investiram na TI com o intuito de obterem alguma vantagem competitiva por meio da informação e não conseguiram.

No sentido de contribuir para a compreensão dos aspectos que podem condicionar esta relação, ou

1. Professor titular da FACECA - PUC-Campinas. 
seja, competitividade e informação, este artigo resgata alguns aspectos que, quando considerados conjuntamente, podem auxiliar na melhoria da gestão do ambiente informacional e, consequentemente, prover condições mais apropriadas para a criação de vantagem competitiva pela informação.

Para isto, explora os elementos básicos que constituem a empresa, os sistema de decisão e seu processo, os sistemas de informação gerencial e a ecologia da informação.

\section{DEFININDO A ORGANIZAÇÃO E SEU AMBIENTE}

\section{Elementos básicos da organização}

Uma organização é um sistema de recursos que procura realizar objetivos ou conjuntos de objetivos. Além de objetivos ou propósito e recursos, conforme propõe Maximiniano (1997), as organizações configuram outros dois elementos importantes: a divisão do trabalho e a coordenação.

\section{Propósito}

As organizações são deliberadamente orientadas para a realização de objetivos que podem ser classificados em duas categorias principais: produtos e serviços. As organizações na medida em que tenham o que oferecer ao mercado esperam estabelecer uma relação de troca com este. Em função do tipo de relação de troca, de produtos e serviços por um preço, por impostos ou uma contribuição, as organizações conseguem estabelecer algum tipo de vantagem no jogo da competitividade.

\section{Divisão do trabalho}

A segunda característica importante das organizações é a divisão do trabalho. Numa organização, cada pessoa e cada grupo de pessoas tem um papel específico que converge para a realização do propósito. Assim como as organizações possuem determinadas competências, as pessoas e os grupos que nelas trabalham também são especializadas em determina- das tarefas. É a divisão de trabalho que permite superar as limitações individuais.

Esta característica determina um desafio que é denominado manutenção da coerência, conforme definido em Corrêa et al (2000), que deve se dar horizontalmente (entre funções) e verticalmente (na mesma função), tendo em vista o propósito geral da empresa.

\section{Coordenação}

Numa organização as diversas tarefas especializadas precisam combinar-se e integrar-se porque elas são interdependentes - para realizar uma, é preciso realizar outra, ou nada acontece.

Interdependência e convergência são palavras-chave no processo de coordenação, a atividade que procura fazer as peças especializadas se encaixarem umas às outras, de modo que o conjunto consiga cumprir sua finalidade. A coordenação funciona por meio de três mecanismos principais: hierarquia, comunicação e planejamento.

\section{- Coordenação por meio da hierarquia}

Em qualquer organização, há uma pessoa ou grupo de pessoas cujo trabalho consiste em desempenhar a tarefa da administração - são os dirigentes. Por meio da autoridade formal ou da liderança, essas pessoas ou grupos conseguem influenciar o comportamento das demais pessoas para que elas executem suas tarefas de maneira coordenada.

Os dirigentes fazem assim o papel de "pinos de ligação" entre as diferentes partes da organização, como a finalidade de integrar as diferentes tarefas especializadas e fazê-las convergir para a realização do objetivo.

\section{- Coordenação por meio de comunicação}

A comunicação entre as pessoas e os grupos de pessoas é o meio pelo qual se transferem e recebem informações e se tomam decisões. É por meio da comunicação que as partes da organização se interligam e articulam suas atividades para funcionar como um conjunto. Em toda organização, existem inúme- 
ros sistemas e processos formais e informais de comunicação e decisão, desde reuniões de diretoria até os bilhetes nos quadros de avisos, desde o correio eletrônico até as conversas de corredor.

Sem informação e comunicação, seja entre os dirigentes ou entre os grupos de trabalho, nenhuma organização consegue funcionar, tomar decisões e muito menos fazer suas partes trabalhar de maneira coordenada.

\section{- Coordenação por meio de planejamento}

Planejamento é o processo de tomar decisão antecipadamente, ou de preparar a tomada de decisão. Se decisões relativas à execução de uma tarefa são planejadas, em vez de improvisadas, e envolvem os responsáveis pelas diferentes partes especializadas em que a tarefa se divide, as partes conseguirão trabalhar de forma coordenada para chegar aonde devem. A coordenação por meio do planejamento é uma arte que se apoia em técnicas altamente desenvolvidas. Não usar essas técnicas é deixar de levar em conta a coordenação que muitas tarefas interdependentes exigem.

\section{As organizações como burocracias}

A palavra burocracia identifica as organizações que se baseiam em regulamentos. Há uma razão extremamente importante para entender o que é burocracia: a sociedade organizacional é, também, uma sociedade burocratizada. A burocracia é um estágio na evolução das organizações. As burocracias tendem a apresentar disfunções, que interferem em seu desempenho. Esse é outro motivo de grande importância para estudar as organizações sob a perspectiva de sua natureza burocrática.

\section{Tipo ideal de burocracia}

As organizações formais, ou burocráticas, apresentam três características principais, que as distinguem dos grupos informais ou primários: formalidade, impessoalidade e profissionalismo, sintetizadas na tabela 1 Essas três características formam o chamado tipo ideal de burocracia, criado por Max Weber. O tipo ideal é um modelo abstrato que procura retratar os elementos que constituem qualquer organização formal do mundo real.

\section{Disfunções das burocracias}

O tipo ideal analisado por Marx Weber procura evidenciar as características das organizações burocráticas em sua forma pura.

Todas as organizações reais contêm os três elementos do tipo ideal, em maior ou menor grau. Paradoxalmente, são, também, diferentes do tipo ideal, porque apresentam disfunções, que as fazem ser ineficientes e ineficazes. As disfunções existem porque as organizações são sistemas humanos e não mecânicos, estritamente regidos pelas leis. A seguir, apresenta-se as seis disfunções principais de que as organizações formais normalmente sofrem:

- valorização dos regulamentos: excesso de regulamentos, regulamentos tornam-se fins em si mesmos.

- valorização da hierarquia: subir na hierarquia não depende de talento, culto aos chefes torna-se objetivo importante.

- defesa de grupos externos: decisões são tomadas em função da associação com grupos externos.

Tabela 1. Principais características das organizações burocráticas, segundo Weber.

\begin{tabular}{|l|l|}
\hline Formalidade & $\begin{array}{l}\text { As burocracias são essencialmente sistemas de normas. A figura da autoridade é definida pela lei, que tem como obje- } \\
\text { tivo a racionalidade da coerência entre meios e fins. }\end{array}$ \\
\hline Impessoalidade & Nas burocracias, os seguidores obedecem à lei. As figuras da autoridade são obedecidas porque representam a lei. \\
\hline Profissionalismo & $\begin{array}{l}\text { As burocracias são formadas por funcionários. Como fruto de sua participação, os funcionários obtêm os meios para } \\
\text { sua subsistência. As burocracias operam como sistemas de subsistência para os funcionários. }\end{array}$ \\
\hline
\end{tabular}


- defesa de interesses pessoais: decisões são tomadas em função de interesses particulares.

- mecanicismo: pessoas desempenham papéis limitados, talentos são subaproveitados.

- individualismo: burocracia estimula competição por vantagens.

\section{Organizações como grupo de pessoas}

Após estudar as organizações como sistemas regidos por regulamentos, que aplicam tecnologia para transformar recursos em produtos e serviços, focalizam-se as pessoas que nelas trabalham. Por alguns instantes, deixe de lado as máquinas e os equipamentos, os laboratórios, as normas e os regulamentos, e preste atenção no comportamento humano. Usando agora um enfoque comportamental, conforme Bateman \& Snell (1999), é possível observar que dentro de qualquer organização formal existe uma organização informal, que tem grande influência sobre o desempenho, e cujos elementos mais importantes são:

- cultura organizacional: que compreende normas de condutas, valores, rituais e hábitos;

- clima organizacional: que compreende os sentimentos manifestos por pessoas e grupos em relação a empresa.

- grupos informais: que compreende os grupos criados por motivos de interesse ou amizade.

A cultura é a experiência que o grupo adquiriu à medida que resolveu seus problemas de adaptação externa e integração interna, e que funciona suficientemente bem para ser considerada válida. Portanto, essa experiência pode ser ensinada aos novos integrantes como forma correta de perceber, pensar e sentir-se em relação a esses problemas.

Os sentimentos manifestam-se em relação a inúmeros aspectos da vida na organização: trabalho, salários, comportamento dos chefes, colegas e instalações físicas são alguns deles. O produto dos senti- mentos individuais e grupais criados por esses aspectos chama-se clima organizacional. O clima é representado pelos conceitos e sentimentos que as pessoas partilham a respeito da organização e que afetam de maneira positiva ou negativa sua satisfação e motivação para o trabalho. Estudar o clima é necessário para entender se a organização e suas práticas administrativas favorecem ou não o interesse e o rendimento das pessoas.

\section{Organização como sistemas}

Uma das idéias fundamentais do enfoque sistêmico é a definição da organização como sistema: uma organização é um sistema composto de elementos ou componentes interdependentes, que podem ter cada um seus próprios objetivos, conforme Maximiniano (1997). Sob a perspectiva do enfoque sistêmico, os limites dos sistemas são arbitrários e dependem do observador, pode-se imaginar uma configuração sistêmica conforme ilustra a Figura 1. Neste modelo estão distinguidos três sistemas (ou subsistemas): o social, o estrutural e o tecnológico.

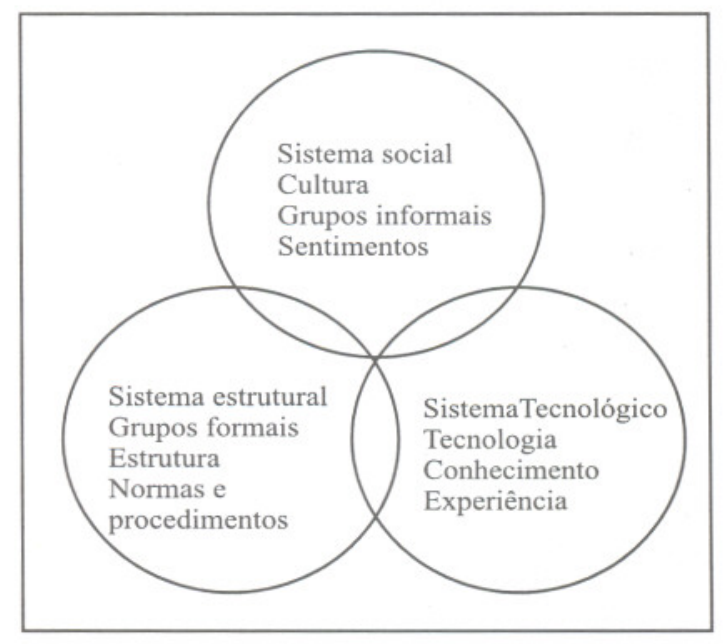

Figura 1. Três subsistemas organizacionais.

\section{A estrutura do ambiente}

$\mathrm{O}$ ambiente de qualquer organização divide-se em duas grandes dimensões. Em primeiro lugar, encontra-se o ambiente imediato, em que estão os segmentos que interessam diretamente à organi- 
zação ou que influenciam diretamente seu desempenho. O ambiente imediato faz parte do macroambiente, ao qual pertencem os segmentos que influenciam todas as organizações semelhantes e a comunidade das organizações em geral. Nos dois casos, ambiente imediato e macroambiente, os segmentos podem organizar-se de forma complexa, formando sistemas externos, que interagem com os sistemas internos.

\section{O ambiente imediato}

O ambiente imediato compreende outras organizações, pessoas e outros tipos de fatores que afetam ou são afetados diretamente pela organização. Os elementos mais importantes do ambiente imediato, entre outros, são os seguintes: cliente, concorrência, fornecedores, distribuidores, sindicatos de empregados e associação de classe.

\section{O macroambiente}

No macroambiente encontram-se organizações, processos e eventos sociais, tecnológicos, institucionais, demográficos e políticos, entre outros. Esses processos afetam a maioria das organizações, ou todas as organizações que compartilham algo, como os mesmos clientes, ou a mesma tecnologia. De acordo com o enfoque sistêmico, é importante reconhecer e avaliar a atuação desses componentes do macroambiente, cujos principais componentes são: tecnologia, ecologia, legislação e instituições, economia, sociedade e demografia.

A Figura 2 ilustra a estrutura geral do ambiente e a organização.

\section{A DECISÃO E SEU PROCESSO}

Os administradores enfrentam problemas constantemente. Alguns problemas requerem decisões relativamente simples; outros, parecem esmagadores. Alguns demandam ação imediata, enquanto outros levam meses, ou mesmo anos para se desdobrarem.

Na realidade, os administradores muitas vezes ignoram os problemas. Por muitas razões evitam agir (conforme Bateman \& Snell, 2000). Primeiro, os administradores não estão certos a respeito de quanto tempo, energia ou dificuldades se escondem atrás de um problema. Em segundo lugar, envolver-se é arriscado: lidar com um problema sem conseguir resolvê-lo satisfatoriamente pode prejudicar os registros da carreira do administrador. Em terceiro, pelo fato de os problemas poderem ser tão desconcertantes, é mais fácil postergá-los ou ocupar-se com atividades que exigem menos.

É importante entender porque a tomada de decisão pode ser tão desafiadora. A maioria das decisões administrativas carecem de estrutura e ensejam risco, incerteza e conflito.

\begin{tabular}{|c|c|c|c|c|}
\hline \multicolumn{5}{|c|}{ Estrutura do ambiente } \\
\hline \multirow{5}{*}{ Ecologia } & Economia & & & \multirow{5}{*}{ Demografia } \\
\hline & & & ncia & \\
\hline & Fornecedores & & $\mathbf{A C C \tilde { A } O}$ & \\
\hline & \multicolumn{3}{|c|}{ Sindicatos/Associação de Classe } & \\
\hline & \multicolumn{3}{|l|}{ Tecnologia } & \\
\hline \multicolumn{3}{|c|}{$\begin{array}{l}\text { Tecnologia: conhecimentos e informações } \\
\text { relativos aos processos e produtos. } \\
\text { Economia: renda, comportamento dos } \\
\text { ajustes econômicos, distribuição da riqueza, } \\
\text { recessão ou expansão, poupança. } \\
\text { Ecologia: meio ambiente físico. }\end{array}$} & \multicolumn{2}{|c|}{$\begin{array}{l}\text { Demografia: taxa de crescimento, composição } \\
\text { étnica. } \\
\text { Legislação e instituições: leis trabalhistas, leis } \\
\text { das sociedades, igrejas, sindicatos. } \\
\text { Sociedade: comportamentos sociais, hábitos, } \\
\text { valores e crenças. }\end{array}$} \\
\hline
\end{tabular}

Figura 2. Ambiente e empresa. 
Ausência de estrutura é o estado usual das questões na tomada de decisões administrativas. Embora, algumas decisões sejam rotineiras e bem definidas, na maioria delas não há um procedimento automático a seguir. Os problemas costumam ser singulares e desestruturados, deixando o tomador de decisões incerto quanto como proceder.

Se possuir toda a informação necessária e se puder prever com precisão as conseqüências das ações, está-se operando sob condições de certeza. Mas certeza perfeita é algo raro. Para decisões administrativas importantes e não programadas, a incerteza é a regra.

Incerteza significa que o administrador não possui informação suficiente para conhecer as conseqüências de diferentes ações. Os tomadores de decisão poderão ter opiniões firmes - podem estar seguros de si mesmos - mais ainda estarão operando sob condições de incerteza se lhes faltam informações pertinentes e se não podem estimar a probabilidade dos diferentes resultados de suas ações.

Quando se estima a probabilidade de várias conseqüências, mas ainda não se sabe com certeza o que irá acontecer, está-se diante de risco. Risco existe quando a probabilidade de uma ação ser bem-sucedida é menor que $100 \%$. Se a decisão for errada, poder-se-á perder dinheiro, tempo, reputação ou outros ativos importantes.

Decisões importantes são ainda mais difíceis por causa do conflito que os administradores enfrentam. O conflito, que existe quando os administradores precisam considerar pressões contrárias de diferentes fontes, ocorrem em dois níveis.

Primeiro, os tomadores de decisão individuais experimentam um conflito psicológico quando várias opções são atrativas, ou quando nenhuma das opções é atrativa. Por exemplo, uma administradora pode ter de decidir quem deverá dispensar, quando não quer dispensar ninguém. Ou então, ela poderá ter três candidatos promissores para apenas uma posição - e aceitar um significa rejeitar os outros dois.
Segundo, conflitos surgem entre indivíduos e grupos. O diretor financeiro argumenta em favor de se aumentar o endividamento a longo prazo para financiar uma aquisição. Entretanto, o conselho diretor prefere minimizar esse endividamento e encontrar os fundos necessários de outra maneira.

\section{O processo racional de tomada de decisão}

Diante desses desafios, como são as boas decisões? O processo decisório ideal deve seguir por seis estágios. Conforme a Figura 3 ilustra, os tomadores de decisão devem
1) identificar e diagnosticar o problema,
2) elaborar soluções alternativas,
3) avaliar as alternativas,
4) fazer a escolha,
5) implementar a decisão e
6) avaliar a decisão.

\section{Identificando e diagnóstico do problema}

O primeiro estágio no processo é reconhecer que existe um problema a ser resolvido. Tipicamente, um administrador percebe algumas discrepâncias entre o estado atual (o modo como as coisas estão) e o estado desejado (o modo como as coisas deveriam estar). Essas discrepâncias - digamos, no desempenho de uma organização ou departamento - podem ser detectadas comparando-se o desempenho atual e (1) o desempenho passado, (2) o desempenho futuro esperado, conforme determinado em planos e previsões.

Reconhecer que o problema existe e é apenas o começo do estágio. O tomador de decisão deve também querer fazer algo a respeito e deve acreditar que os recursos e habilidades para resolver o problema existem. Então, o tomador de decisão deve averiguar mais profundamente e tentar diagnosticar a verdadeira causa que o sintomas do problema revelaram. 


\section{Elaboração de soluções alternativas}

No segundo estágio, o diagnóstico do problema está ligado ao desenvolvimento de cursos de ação alternativos direcionados a sua solução. Os administradores geram pelo menos algumas soluções alternativas com base em experiências passadas.

As soluções variam desde prontas até aquelas feitas sob medida. Os tomadores de decisão que buscam soluções prontas utilizam idéias que viram ou tentaram anteriormente ou seguem as recomendações de outras pessoas que enfrentaram problemas semelhantes. Soluções sob medida, por outro lado, devem ser projetadas para problemas específicos. Essa técnica requer uma combinação de idéias em soluções novas e criativas.

Escolher uma alternativa pronta é muito mais fácil do que projetar uma decisão sob medida. Por essa razão, a maioria dos tomadores de decisão utilizam uma abordagem de alternativa pronta, algumas vezes mesmo quando ela é inadequada. Se essa abordagem falha na obtenção de uma solução aceitável, começa o trabalho mais difícil de se imaginar uma solução única. Para decisões importantes e irreversíveis, devem ser desenvolvidas alternativas sob medida porque elas têm mais chances de conduzir a soluções de maior qualidade.

\section{Avaliação de alternativas}

O terceiro estágio envolve a determinação do valor ou da adequação das alternativas geradas. Qual solução será a melhor?

Muito freqüentemente as alternativas são avaliadas com pouca reflexão ou lógica. É fundamental nesse processo prever as conseqüências que poderão ocorrer se as várias opções forem efetivadas.

Os administradores devem considerar diversos tipos de conseqüências. Obviamente, devem tentar prever esses efeitos em mensurações financeiras ou em outras formas de desempenho, mas existem outras conseqüências menos claras a considerar. Decisões abrem um precedente: esse será uma ajuda ou um obstáculo no futuro? Além disso, o sucesso ou fracasso da decisão irá para os registros daqueles envolvidos no processo decisório.

Deve-se retornar às metas originais. Quais metas cada alternativa atende ou deixa de atender? Quais alternativas são mais aceitáveis para o tomador de decisão e para outros públicos interessados? Se várias alternativas podem resolver o problema, qual delas pode ser implementada ao custo mais baixo? Se nenhuma das alternativas atende às metas, talvez se possa combinar duas ou mais entre as melhores.

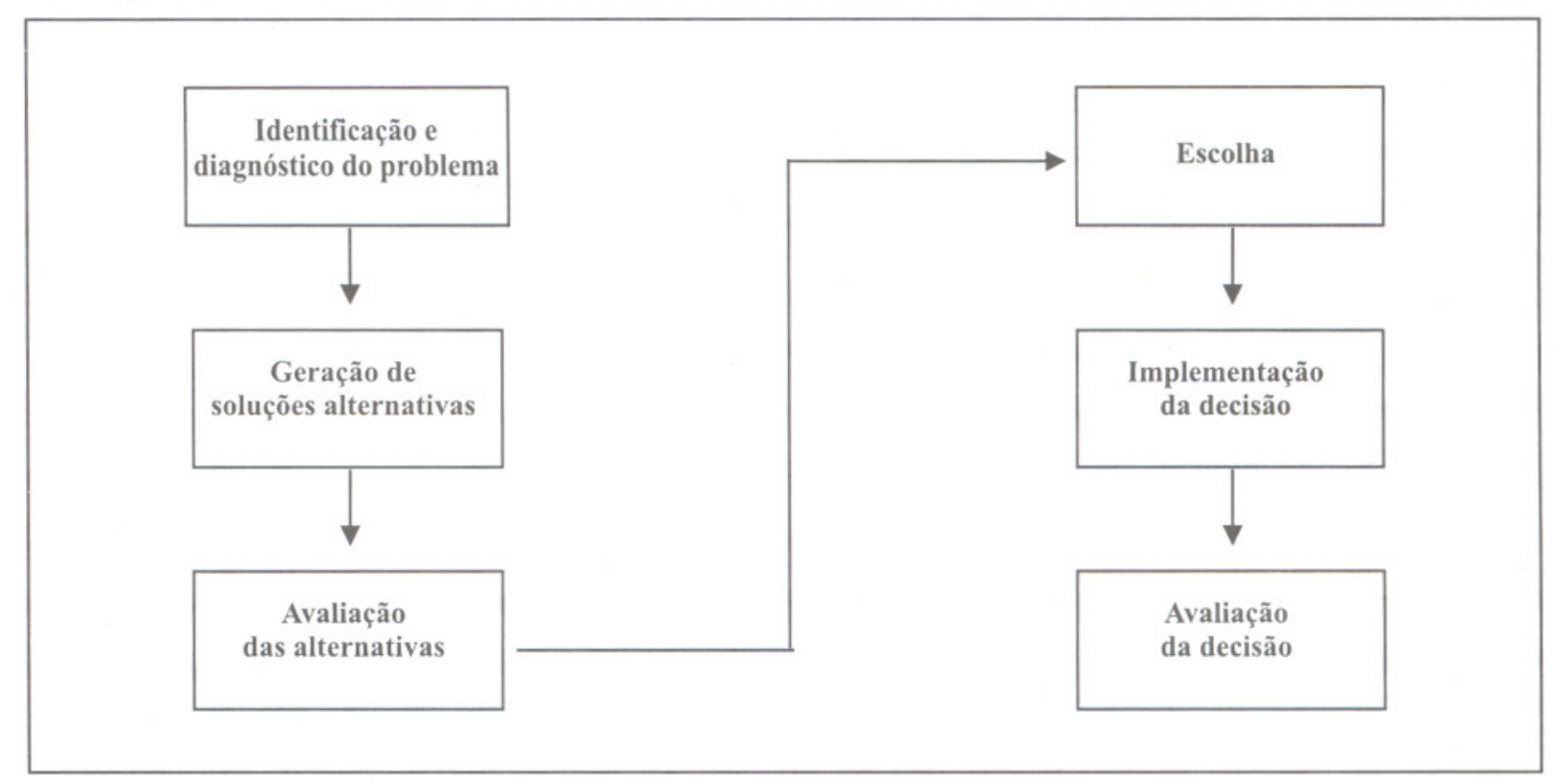

Figura 3. Os estágios da tomada de decisão. 


\section{Fazer a escolha}

Uma vez que se tenha considerado as possíveis conseqüências das opções, é momento de se tomar a decisão. Conceitos importantes nesse estágio são maximização, satisfação.

Maximizar é tomar a melhor decisão possível. A decisão de maximização resulta nas mais positivas conseqüências e no mínimo de conseqüências negativas. Em outras palavras, a maximização resulta no máximo benefício ao menor custo, com o maior retorno esperado. A maximização requer uma busca ampla para que se tenha uma gama completa de alternativas que possam ser avaliadas e comparadas cuidadosamente, para então se escolher a melhor.

Satisfazer é escolher a primeira opção minimamente aceitável ou adequada; a escolha parece atingir uma meta ou critério-alvo. Quando se satisfaz, compara-se a solução obtida com as metas e não com outras alternativas de solução. A satisfação significa que a busca por alternativas termina quando se encontra a primeira que resolva o problema. Normalmente, as pessoas não gastam tempo ou energia para reunir informação completa. Em vez disso, é tomada decisão conveniente com base em informações prontamente disponíveis.

\section{Implementação da decisão}

O processo decisório não termina quando uma escolha é feita. A alternativa escolhida precisa ser implementada. Algumas vezes as pessoas envolvidas na escolha devem efetuá-las. Em outras ocasiões, delegam as responsabilidades pela implementação a outras pessoas, como no caso de uma equipe administrativa que modifica uma política ou procedimentos operacionais e possui supervisores de primeira linha para levar a mudança adiante.

Aqueles que implementam a decisão devem entender a escolha e porque foi feita. Devem também estar compromissados com o sucesso da implementação. Essas necessidades podem ser atendidas pelo envolvimento dessas pessoas desde os primeiros estágios do processo de implementação.
Os administradores devem planejar a implementação cuidadosamente. Um planejamento adequado requer vários passos:

1. Determinar como as coisas estarão quando a decisão for totalmente operacional.

2. Ordenar cronologicamente, talvez com um diagrama do fluxo, os passos necessários para se chegar a uma decisão totalmente operacional.

3. Listar os recursos e atividades necessários para implementar cada passo.

4. Estimar o tempo necessário para cada passo.

5. Atribuir a responsabilidade de cada passo para indivíduos específicos.

\section{Avaliação das decisões}

O estágio final do processo decisório é a validação da decisão. Isso significa coletar informações sobre quão bem a decisão está operando. As metas quantificáveis - $20 \%$ de crescimento nas vendas, $80 \%$ de redução de acidentes, $100 \%$ de entregas dentro do prazo - podem ser estabelecidas mesmo antes de a solução do problema ser efetuada. Então, dados objetivos podem ser coletados para se determinar criteriosamente o sucesso (ou fracasso da decisão).

A avaliação da decisão é útil se o feedback é positivo ou negativo. Um feedback que sugere que a decisão está funcionando implica que a decisão deve ser continuada e talvez aplicada por toda a empresa. Um feedback negativo, que indica fracasso, significa que ou (1) a implementação requer mais tempo, recursos, esforços ou reflexão, ou (2) que a decisão é ruim.

Se a decisão mostra-se inadequada, deve voltar à prancheta de rascunhos. O processo retorna ao primeiro estágio, preferivelmente com mais informação, novas sugestões e uma abordagem que procure eliminar os erros cometidos na primeira vez. 


\section{Como são realmente tomadas} as decisões nas organizações ?

Os tomadores de decisão nas organizações são racionais? Examinam cuidadosamente os problemas, identificam todos os critérios relevantes, utilizam sua criatividade para identificar todas as alternativas viáveis e diligentemente avaliam todas para encontrar aque otimizará o resultado? Em algumas situações, sim. Quando quem toma decisão se defronta com um problema simples com poucos cursos de ação alternativos, e quando, o custo de procurar e avaliar as alternativas é baixo, o modelo racional fornece uma descrição bastante precisa do processo de decisão. Mas tais situações são exceção. A maioria das decisões no mundo real não segue o modelo racional. As pessoas normalmente se contentam em achar uma solução aceitável ou razoável para o seu problema em lugar de encontrar uma solução otimizante. Dessa, forma, os tomadores de decisão geralmente fazem uso limitado de sua criatividade. As escolhas tendem a confinar-se às imediações do sintoma do problema e da alternativa corrente, conforme Robbins (2000). Além disso, embora um número crescente de tomadores de decisão conheça e seja capaz de utilizar a análise quantitativa, eles raramente o fazem. E quando o fazem, quase sempre é para apoiar objetivamente decisões que foram tomadas subjetivamente. Como concluiu um especialista em processos de decisão: "a maioria das decisões importantes são tomadas por meio de julgamento e não por um modeloprescritivo definido"(Simon, 1997). Os tópicos a seguir analisam um grande conjunto de dados para apresentar uma descrição de comó a maioria das decisões nas organizações são realmente tomadas.

\section{Racionalidade delimitada}

Quando confrontada com um problema complexo, a maioria das pessoas responde pela redução do problema em um nível no qual ele possa ser prontamente entendido. Assim o fazem porque a limitada capacidade dos seres humanos de processar infor- mações impossibilita assimilar e compreender todas as informações necessárias a otimizar. Por isso, as pessoas se acomodam, ou seja, buscam soluções que sejam satisfatórias e suficientes.

Uma vez que a capacidade da mente humana para formular e resolver problemas complexos é pequena demais para atender aos requisitos da racionalidade plena, os indivíduos operam dentro dos limites da racionalidade delimitada. Constróem modelos simplificados que captam as características essenciais dos problemas sem considerar toda a sua complexidade. Os indivíduos podem, então, comportar-se racionalmente dentro dos limites do modelo simples.

Como opera a racionalidade delimitada para o indivíduo normal, na concepção de Simon (1997)? Uma vez identificado um problema, começa a procura de critérios e alternativas. Mas é provável que a lista de critérios esteja longe de ser exaustiva. O tomador de decisão identificará uma lista limitada composta das opções mais explícitas. São as opções fáceis de se encontrar e que tendem a ser extremamente visíveis. Na maioria dos casos, representarão critérios conhecidos e soluções testadas e comprovadas. Uma vez identificado esse conjunto de alternativas, começará a analisá-las. mas a análise não será abrangentenem todas as alternativas serão cuidadosamente avaliadas. Em lugar disso, o tomador de decisão começará com alternativas que difiram apenas num grau relativamente pequeno da escolha comumente adotada. Seguindo caminhos conhecidos e bem trilhados, ele passará a analisar alternativas apenas de desempenho. A primeira alternativa que atender ao critério do "suficientemente boa" encerrará a procura. Portanto, a solução final representa uma escolha de acomodação, em lugar de uma escolha ótima. A Figura 4 ilustra o processo racional de decisão, denominado racionalidade delimitada.

Lembre-se: no modelo plenamente racional otimizante, todas as alternativas são finalmente listadas em uma ordem hierárquica de preferência, dado que todas serão consideradas, a ordem inicial na qual 


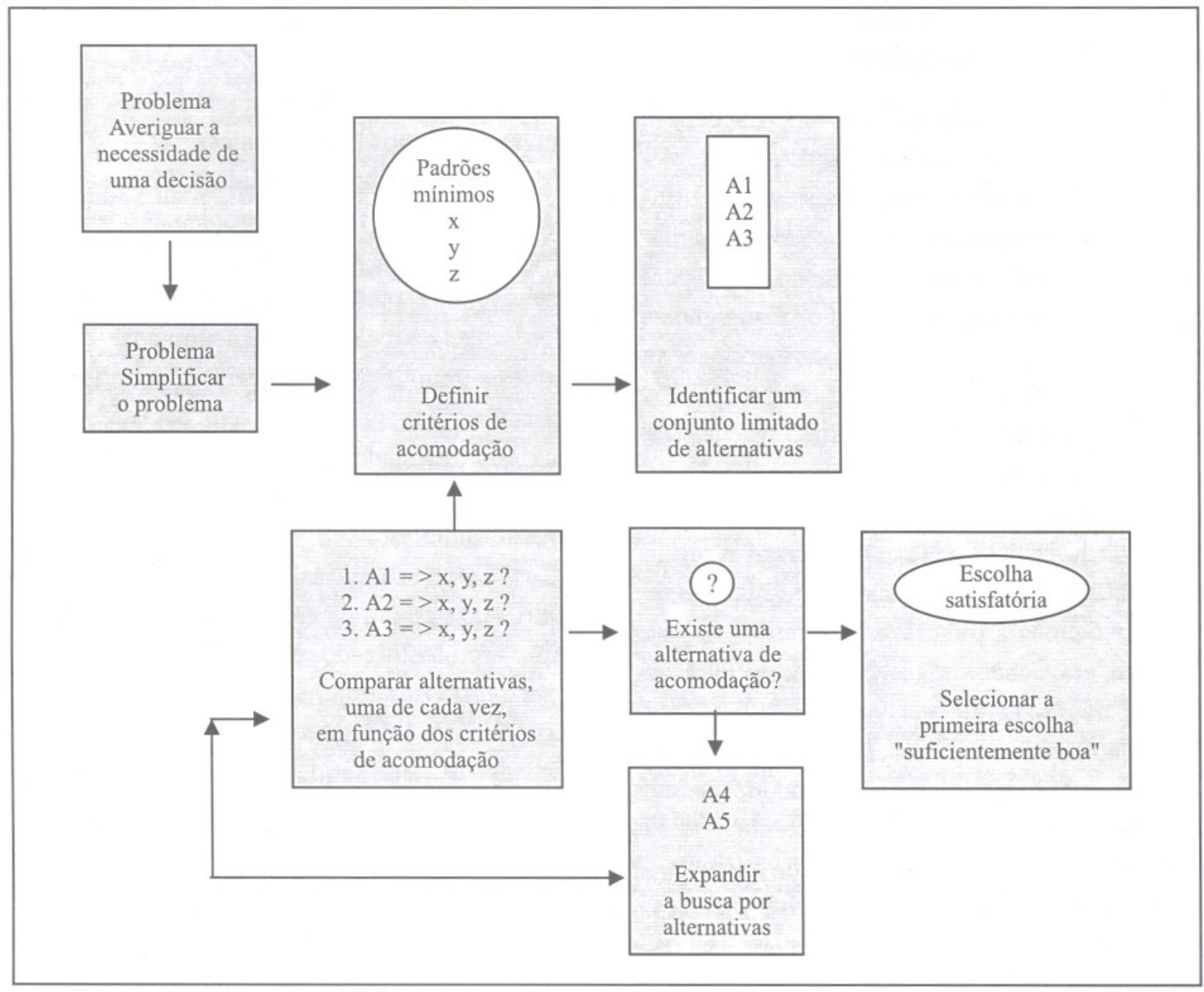

Figura 4. Um modelo de racionalidade delimitada. Adaptada de Robbins (2000).

são avaliadas é irrelevante. Toda solução potencial passa por avaliação completa e exaustiva. Mas isso não é verdade na racionalidade limitada. Se um problema tem mais de uma solução potencial, a escolha de acomodação será a primeira aceitável encontrada pelo tomador de decisão. Uma vez que os tomadores de decisão utilizam modelos simples e limitados, normalmente começam por identificar alternativas óbvias, aquelas com que estão familiarizadas, e aquelas que menos se afastam da situação existente. Assim, tendem a ser selecionadas as soluções que menos se afastam da situação existente e atendem aos critérios da decisão. Uma alternativa única e criativa pode apresentar uma solução otimizadora para o problema, mas é improvável que seja escolhida, pois uma solução aceitável será identificada bem antes que o tomador de decisão seja obrigado a ir procurar soluções distantes da situação existente.

\section{Intuindo}

“Às vezes você simplesmente precisa seguir o que seu coração manda", dizia a gerente ao tentar explicar como escolheu entre dois candidatos qualificados para o cargo. Ela está errada? O uso dos sentimentos é sinal de um gerente deficiente? Resulta necessariamente em um resultado inferior? A resposta a todas estas perguntas é não. Os gerentes usam constantemente sua intuição e esta pode de fato ajudar a melhorar a tomada de decisão.

Definição: Primeiro, define-se o que se quer dizer por decisão intuitiva. Há várias maneiras de conceituar a intuição. Alguns, por exemplo, conside- 
ram-na uma forma de poder extra-sensorial ou sexto sentido, outros acreditam que ela é uma traço de personalidade inato a um número limitado de pessoas. Para o propósito deste artigo, define-se decisão intuitiva como o processo inconsciente criado a partir de um refinamento da experiência. Esse processo não opera necessariamente de um modo independente da análise racional, mas precisamente, os dois se complementam entre si.

Teoria da Imagem: A teoria da imagem oferece uma explicação abrangente de como a maioria das pessoas utiliza a intuição para tomar decisões. Como ela é bastante complexa, com base em seus elementos principais mostraremos como as pessoas a utilizam para tomar decisões tais como: devo eu adotar um determinado curso de ação?

Existem três elementos básicos na teoria da imagem: imagens, testes e quadros. Os tomadores de decisão são orientados por três visões diferentes, chamadas imagens. A primeira representa os princípios ou valores básicos de um tomador de decisão; a segunda as metas ou fins aspirados por quem está tomando a decisão e a terceira imagem os planos ou meios para alcançar essas metas.
Há dois testes pelos quais as decisões são tomadas. $\mathrm{O}$ teste de compatibilidade, que determina se uma alternativa se ajusta aos princípios, metas e planos adotados, e o teste de rentabilidade, que compara conseqüências potenciais de uma alternativa contra as de outras. Enquanto o objetivo do teste de compatibilidade é eliminar o inaceitável, o teste de rentabilidade busca a melhor opção.

Estruturas dizem respeito ao contexto de uma decisão ou como as informações são apresentadas. A conhecida pergunta "a garrafa está cheia ou meio vazia ?" é uma questão de estrutura. Estruturação é importante, porque a teoria de imagem afirma que o contexto no qual ocorrem as decisões confere-lhes significado, e que os sucessos e fracassos do passado em contextos iguais ou semelhantes fornecem orientação sobre o que fazer quanto à decisão atual. Portanto, a estruturação permite ao tomador de decisão utilizar sua intuição para decidir o que fazer dessa vez.

Dados os conceitos e definições anteriores, eis o que propõe a teoria da imagem (veja Figura 5).

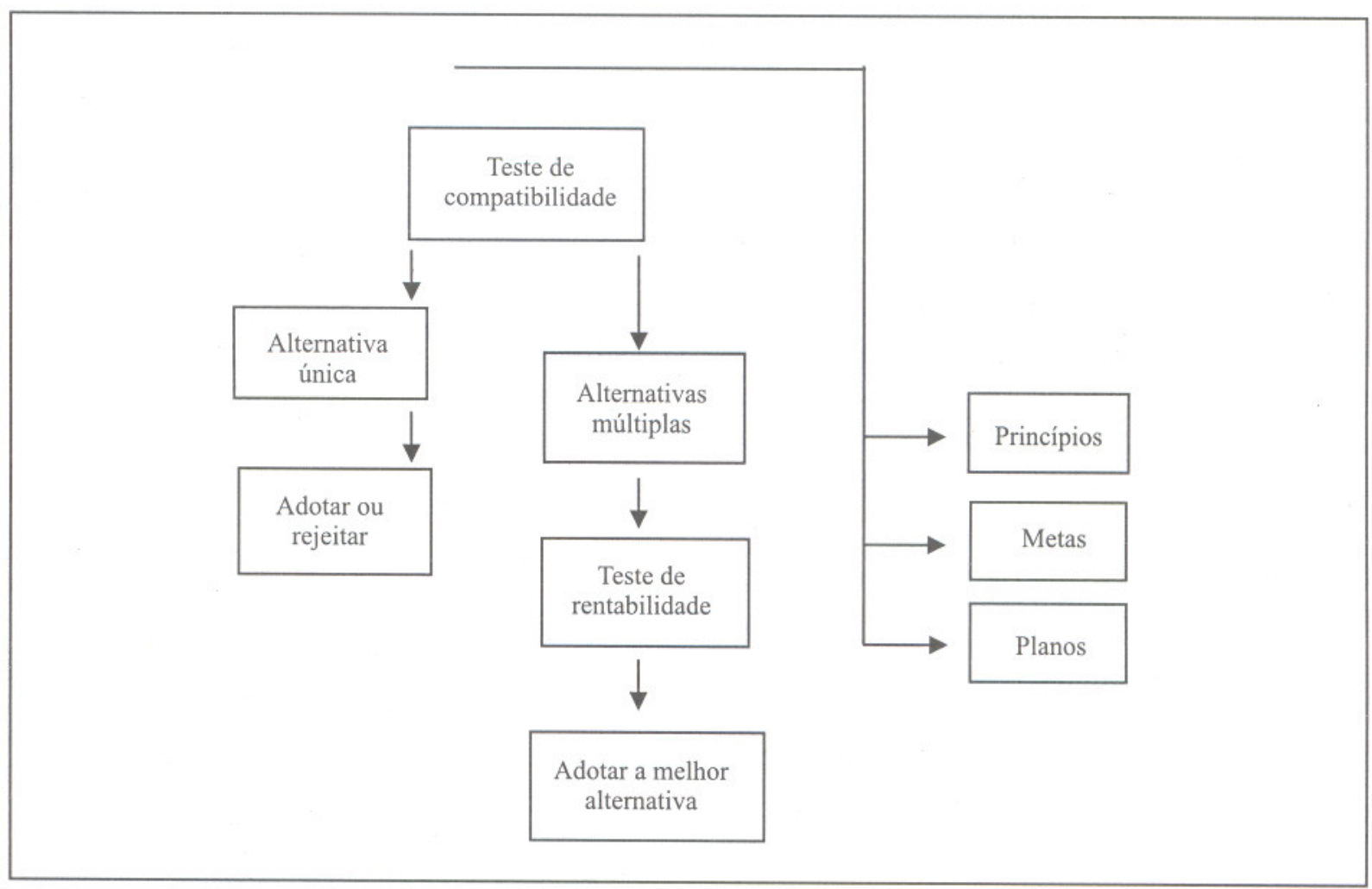

Figura 5. Modelo intuitivo do processo de decisão. Adaptado de Robbins (2000). 
Tomar decisões é essencialmente um processo automático e intuitivo, que requer uma quantidade mínima de raciocínio. Os indivíduos fazem sua escolha com base em um processo simples de dois passos. Primeiro, uma opção precisa passar pelo teste de compatibilidade. Ela ajusta-se aos princípios, metas e planos do tomador de decisão? Em caso positivo, e se nenhuma outra opção concorrente também se ajustar, essa opção é adotada. Aliás, esta opção é sinônimo de uma escolha de acomodação. Se a opção não passar pelo teste de compatibilidade, será rejeitada. A maioria das decisões não vai um pouco além desse passo, ou seja, há apenas uma alternativa que é considerada, que ou é "suficientemente boa" ou não é! Nos casos em que existem múltiplas alternativas e duas ou mais passam no teste de compatibilidade, é necessário um segundo passo, o teste de rentabilidade, mais complexo e deliberativo. Ambos os testes são influenciados pela estrutura do tomador de decisão, que avalia as informações no contexto de experiências passadas. Portanto, a estruturação tende a destruir a objetividade, pois estimula os tomadores de decisão a formar rapidamente uma opinião sobre uma situação de decisão para, em seguida, desenvolver e avaliar uma alternativa com base em sua intuição.

\section{O SISTEMA DE INFORMAÇÃO}

A Figura 6 ilustra um modelo de sistemas de informação que expressa uma estrutura conceitual fundamental para os principais componentes e atividades dos sistemas de informação. Um sistema de informação depende dos recursos humanos (os usuários finais e os especialistas em SI), de hardware (máquinas e mídia), software (programas e procedimentos), dados (bancos de dados e bases de conhecimento) e redes (mídia de comunicação e apoio de rede) para executar atividades de entrada, processamento, armazenamento e controle que convertem recursos de dados em produtos de informação.

Este modelo de sistema de informação destaca as relações entre os componentes e atividades dos sistemas de informação. Ele fornece uma estrutura referencial que enfatiza quatro conceitos principais que podem ser aplicados a todos os tipos de sistemas de informação.

- Pessoas, hardware, software, dados e redes são os cinco recursos básicos dos sistemas de informação.

- Os recursos humanos incluem os usuários finais e especialistas em SI, os recursos de hardware consistem em máquinas e mídia, os recursos de software incluem programas e procedimentos, os recursos de dados podem incluir bancos de dados e bases de conhecimento e os recursos de rede incluem mídia e redes de comunicação.

- Os recursos de dados são transformados por atividades de processamento de informação em uma diversidade de produtos de informação para os usuários finais.

- O processamento de informação consiste em atividades de entrada, processamento, saída, armazenamento e controle.

Exemplos de recursos e produtos dos sistemas de informação.

- Recursos Humanos

1. Especialistas - analistas de sistemas, programadores, operadores de computador;

2. Usuários finais - todos os demais que utilizam sistemas de informação.

- Recursos de Hardware

1. Máquinas - computadores, monitores de vídeo, unidades de disco magnético, impressoras, scanners óticos.

2. Mídias - disquetes, fita magnética, discos óticos.

- Recursos de Software

1. Programas - sistemas operacionais, planilhas eletrônicas, processamento de texto, folha de pagamento.

2. Procedimentos - procedimentos de entrada de dados, de correção de erros, de distribuição da informação. 


\section{- Recursos de Dados}

1. Descrição de produtos, cadastro de clientes, arquivos de funcionários, banco de dados de estoque.

- Recursos de Rede

1. Meios de comunicação, processadores de comunicação, acesso a redes e software de controle.

\section{- Produtos de Informação}

1. Relatórios administrativos e documentos empresariais utilizando texto e demonstrativos gráficos, respostas em áudio e formulários em papel.

Vale a pena destacar as diferenças entre dados e informação, que segundo Oliveira (2000):

- dado - é qualquer elemento identificado em sua forma bruta que, por si só, não conduz a uma compreensão de determinado fato ou situação;

- informação - é dado trabalhado que permite ao executivo tomar decisões.

\section{Atividades dos sistemas de informação}

Identificamos as atividades de entrada, processamento, saída, armazenamento e controle que ocorrem em todo sistema de informação. Como exemplos das atividades básicas dos sistemas de informação, tem-se:

- Entrada-escaneamento ótico de etiquetas com código de barras em mercadoria;

- Processamento - calcular salário, impostos e outras deduções na folha de pagamento dos funcionários;

- Saida - produzir relatórios e demonstrativos de desempenho das vendas;

- Armazenamento - manter registros sobre clientes, empregados e produtos;

- Controle - gerar sinais audíveis para indicar entrada adequada de dados de venda.

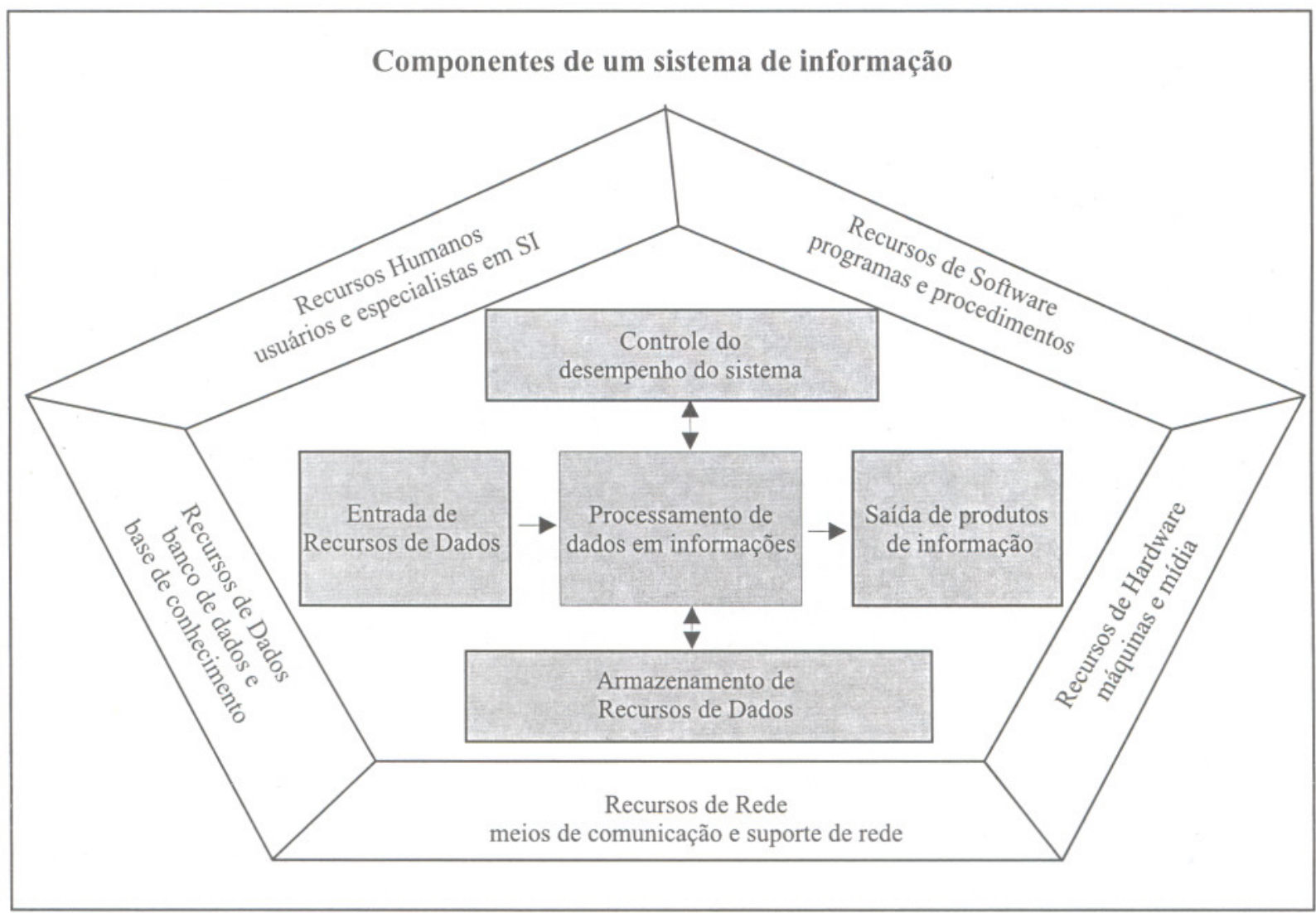

Figura 6. Os componentes do sistema de informação. Adaptado de O’Brien (2000). 


\section{Tipos de sistemas de informação}

Em termos conceituais, os sistemas de informação no mundo real podem ser classificados de maneiras diferentes. Vários tipos de sistemas de informação, por exemplo, podem ser classificados conceitualmente ora como operações ora como sistemas de informação gerencial. A Figura 7 ilustra esta classificação conceitual dos sistemas de informação. Eles são classificados desta maneira para destacar os papéis principais que cada um desempenha nas operações e administração de uma empresa.

Os sistemas de apoio às operações processam dados gerados por operações empresariais. As principais categorias são:

- sistemas de processamento de transaçõesprocessam dados resultantes de transações empresarias, atualizam banco de dados operacionais e produzem documentos empresarias;

- sistemas de controle de processos monitoram e controlam processo industriais;

- sistemas colaborativos - apoiam equipes, grupos de trabalho bem como comunicações e colaboração nas e entre empresas.

Os sistemas de apoio gerencial fornecem informações e apoio necessários para tomada de decisão eficaz pelos gerentes. As principais categorias são:

- sistemas de informação gerencial - que fornecem informações na forma de relatórios e demonstrativos pré-estipulados para os gerentes;

- sistemas de apoio à decisão - que fornecem apoio interativo ad hoc para o processo de decisão dos gerentes;

- sistemas de informação executiva - que fornecem informações críticas elaboradas especificamente para as necessidades de informação dos executivos.
Outras categorias de sistemas de informação podem apoiar decisões operações, gerenciais estratégicas, conforme Rezende \& Abreu (2000). Nesta classificação os sistemas de informação operacional (SIO) têm a mesma definição apresentada; os sistemas de informação gerencial (SIG) compreendem os sistemas típicos, contemplam o processamento de grupos de dados das operações e transações operacionais, transformando-os em informações agrupadas para a gestão. Apoiam a tomada de decisão no âmbito das unidades departamentais, em sinergia com as demais unidades. Por fim, os sistemas de informação estratégicos (SIE) que são, também, chamados de sistemas de Informação Executiva. Contemplam o processamento de grupos de dados de operações e transações gerenciais, transformando-os em informações estratégicas. Trabalham com os dados em termos macro, filtrados das operações das funções empresariais da empresa, considerando, ainda, o meio ambiente interno e/ou externo, visando a auxiliar o processo de tomada de decisão da alta administração, tal como presidentes, diretores, sócios, acionistas, proprietários.

Habitualmente, trabalham com muitas informações gráficas, amigáveis e normalmente online, observando as particularidades de cada empresa e, ainda, com opção de descer no nível de detalhe da informação.

Estes sistemas podem ser utilizados para auxiliar decisões que foram articuladas a partir de processos racionais de tomada de decisão, conforme Oliveira (1999) propõe. Desta forma, o pressuposto básico é que os dirigentes das empresas utilizam processos racionais de tomada de decisão e, consequentemente, utilizam tais sistemas para apoiá-los. Todavia, resultados empíricos como os relatados em Caldas \& Wood (2000), quando identifica os motivos que levam as empresas a adquirir sistemas integrados de informação, demonstram que a melhoria do processo decisório não é uma preocupação ou critério para justificar a aquisição de sistemas que tratam a informação. 


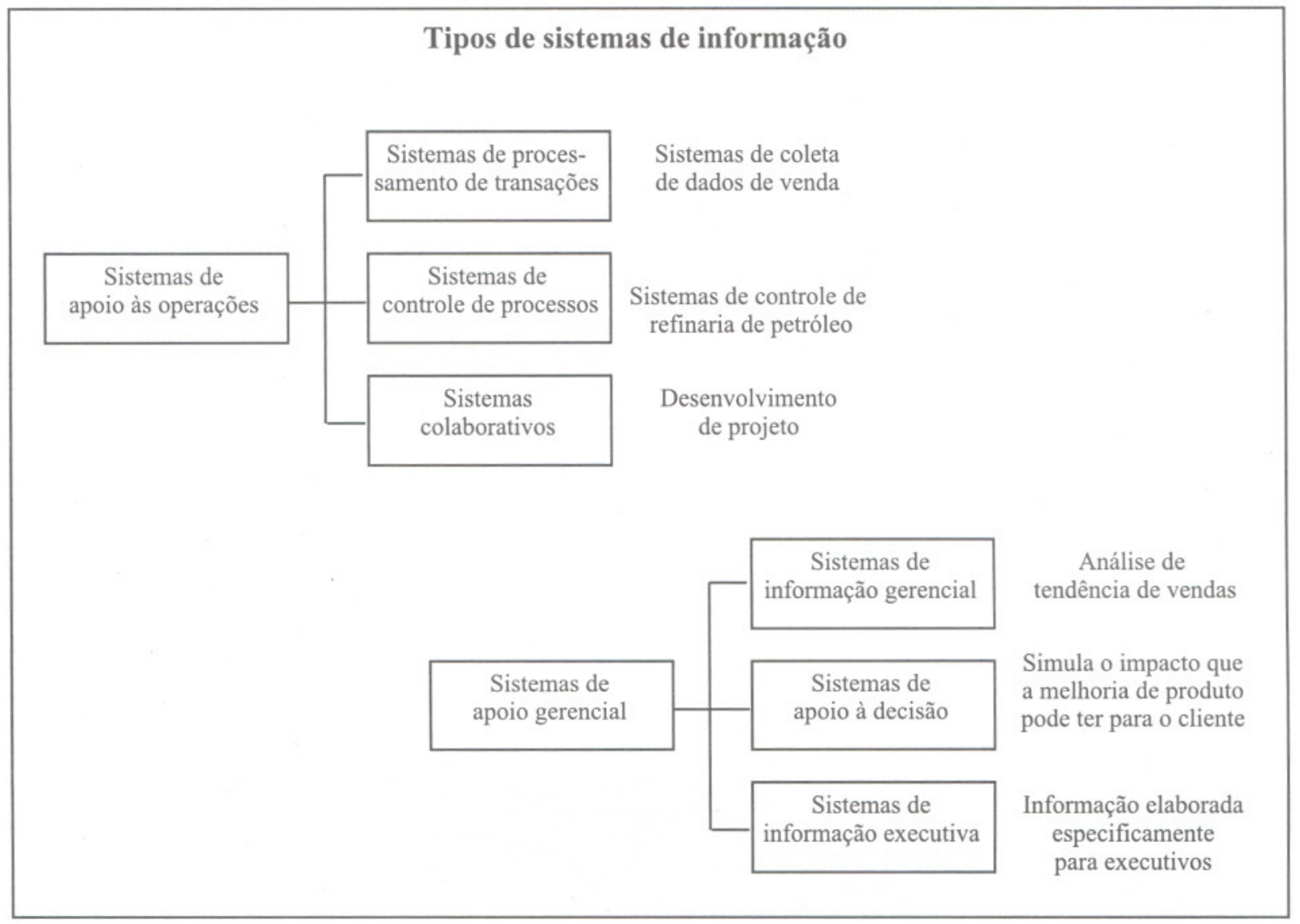

Figura 7. Classificação dos sistemas de informação. Adaptado de O'brien (2000).

\section{A ECOLOGIA DA INFORMAÇÃO}

Se a empresa fosse eminentemente burocrática, se seus objetivos fossem eminentemente financeiros, se as decisões tomadas fizessem usos exclusivo do processo racional, possivelmente, o SIG e suas versões mais elaboradas, que incorporam os mais diversos modos de tratamento de dados transformando-os em informação, conforme Shimizu (2000), e apresentação em tela, conforme O'Brien (2000), obter vantagem competitiva por meio do uso da informação tornaria algo sem significado.

Felizmente, a empresa é também informal, seus objetivos extrapolam os objetivos puramente financeiros, o processo de decisão muitas vezes utilizado é o intuitivo, sustentado por um conhecimento tácito, e o próprio mundo da informação não se restringe ao mundo computacional, em que os inocentes acreditam ser capazes de armazenar toda informação que a empresa necessita para criação e sustentação de alguma vantagem competitiva.

O reconhecimento destes fatos reforçam a importância de reconhecer e ter implementado o conceito de ecologia de informação proposto em Davenport (1998), no sentido de revisar a gestão da informação, tendo em vista a necessidade de redimensionar o ambiente informacional da empresa. Este redimensionamento deve proporcionar condições mais favoráveis para que se possa reconhecer outros contextos que contêm informações diferentes dos tradicionais ambientes computacionais, ou seja, a ecologia da informação explicita a diversidade que é o mundo da informação. Nele é reconhecida a necessidade de desenvolver mecanismos capazes de tratar informações estruturadas e não-estruturadas, visuais, sonoras e escritas, provenientes de diferentes fontes. 
A Figura 8 ilustra o modelo de referência de gestão da informação com enfoque ecológico.

Os elementos que compõem o ambiente informacional não só dimensionam o próprio mundo da informação, mas também redimensiona o próprio mundo da empresa, na medida em que recoloca aspectos que são abordados apenas no contexto da teoria das organizações e que foram tratados anteriormente, a saber: burocracia, organização informal, cultura, ambiente. Integrando os dois mundos num único contexto. dados e as informações tornam-se mais estruturadas e podem sofrer condicionamentos tais que permitem seu armazenamento em sistemas tipo ERP (Enterprise Resource Planning), conforme modelo apresentado em Filho (2001).

É importante entender que informações estruturadas compõem parte da ecologia. Assim informações armazenadas em sistemas integrados de informação atendem bem a objetivos táticos e operacionais, conforme Silva \& Rodrigues (2001), e como

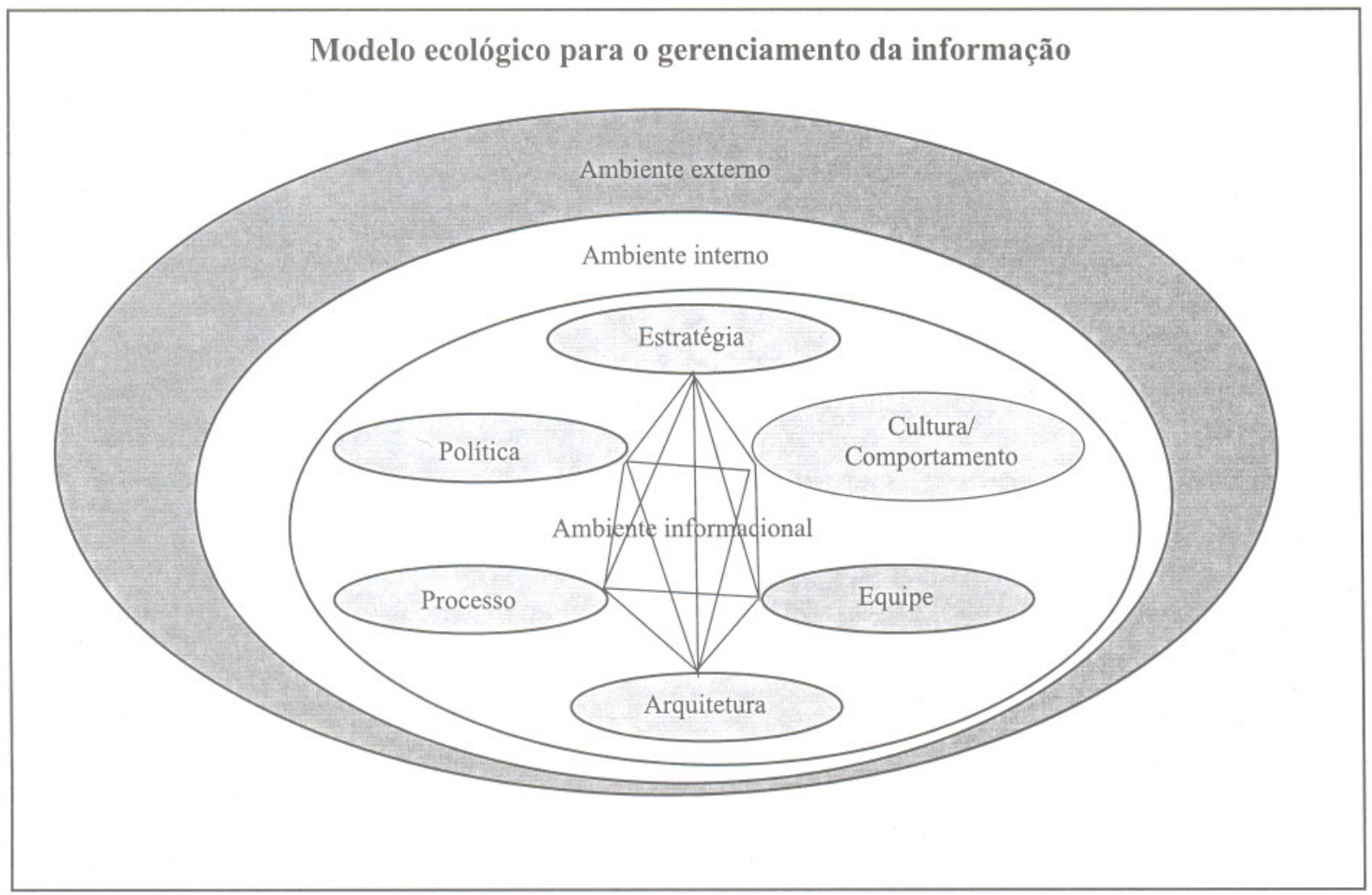

Figura 8. O modelo de gestão da informação. Adaptado de Davenport (1998).

A diversidade da informação, por sua vez, permeia os níveis estratégicos, táticos e operacionais, na forma como propõe Drucker (1999), ou McGee \& Prusak (1985), quando tratam da articulação de informações que permitem a empresa analisar seu ambiente para a formulação de estratégia.

Informações estratégicas são predominantemente não-estruturadas e surgem desorganizadamente, conforme argumenta Drucker (1999). Na medida em que se focalizam os aspectos rotineiros os demonstra pesquisa apresentada por Nanini (2001), ou seja, para possibilitar rápidas avaliações de desempenho interno da empresa e elaboração de medidas corretivas que eliminem as causas de problemas que estejam sendo os responsáveis por tais desempenhos, pois as informações internas atendem satisfatoriamente estas necessidades.

A ecologia da informação resgata também o reconhecimento da organização informal e propõe que, 
quando for estabelecida a estratégia de informação, esta considere, por meio do estabelecimento de princípios, que a empresa focalize a cultura e comportamento organizacional em relação a informação. Esta consideração, por si só, incorpora um aspecto orgânico no tratamento da informação, aspecto este que não é considerado por abordagens tradicionais que sustentam a incorporação dos SI (Sistemas de informação) na vida das empresas.

Sem a pretensão de ser a solução dos problemas advindos da não aderência entre informação e competitividade, mas colocando uma esperança sobre esta questão, a ecologia da informação propõe que esteja submetida à estratégia organizacional a estratégia informacional. De tal modo, que a produção da informação deve seguir um processo explícito e gerenciável tendo em vista o tipo de ganho que a empresa pretende obter em termos organizacionais. Desta forma, extrapola a proposta de Rezende \& Abreu (2000), que aborda apenas a informação que pode ser tratada por sistemas computacionais, ou seja, a produção de informações por procedimentos pré-concebidos e utilizados estaticamente, ou de forma dinâmica, de tal modo que as informações são produzidas por sistemas dinâmicos, na forma que propõe Rezende \& Abreu (2000). Estes sistemas dinâmicos requerem, para sua concepção, a participação direta do dirigente, usuário, com a equipe de desenvolvimento. Tem em sua origem informações produzidas por processamento prévio que induzem a equipe a desenvolver um novo sistema, configurando um ciclo dinâmico de desenvolvimento.

Reforça a necessidade de serem criados mecanismos pouco convencionais que desatrelam a arquitetura da informação daquela que tem o enfoque puramente de engenharia computacional no conceito de Prezam (1995), complementando a proposta de Rezende \& Abreu (2000). Argumentando que fontes de informação muitas vezes são mais importantes do que a própria informação, Davenport (1998) propõe que seja construído um mapa que indique fontes de informação, independentemente destas estarem armazenadas eletronicamente. Portanto, este mapa pode conter informações que referenciam pessoas que possuem determinados conhecimentos que podem ser úteis a outras pessoas dentro e fora da empresa.

\section{CONSIDERAÇÕES FINAIS}

Neste artigo foi construído um referencial teórico para representar a empresa e o sistema de decisão que representa a sua força motriz no processo de elaboração de estratégia competitiva.

A informação representa a matéria-prima desta força motriz e seu tratamento, conforme proposto, não pode se restringir àquele dado pelos sistemas de informação. Na medida em que nem todas as informações necessárias para decisões estratégicas são estruturadas, permitindo tratamento sistemático e, em menor dimensão, o mesmo acontecendo para a manutenção das operações internas que sustentam o funcionamento do sistema empresa. Surge então a necessidade de reconhecer a diversidade da informação e, consequentemente, construir um sistema de gestão da informação que considere o seu aspecto ecológico, buscando fundir no sistema de gestão da empresa a gestão ecológica da informação. Apesar de desafiador, o reconhecimento da diversidade da informação e a construção de uma gestão ecológica, pelo menos em termos conceituais, liberta a empresa dos sistemas puramente computacionais, e a coloca na direção de uma abordagem mais orgânica, tornando o tratamento da informação mais compatível com a dinâmica empresarial.

Esta proposta redimensiona o sistema informacional a ser considerado pela empresa, e cria condições para que se possa avançar na direção de construir uma vantagem competitiva por meio da informação, dando uma chance à empresa de eliminar o hiato existente entre competitividade e informação. 


\section{REFERÊNCIAS BIBLIOGRÁFICAS}

BATEMAN, T. S; SNELL, S. A. Administração. Construindo vantagem competitiva. São Paulo: Atlas, 1998.

CALDAS, M. P; WOOD, T. J. Fads and Fashions in management: the case of ERP. Revista RAE, vol. 40, n. 3, pp. $8-17$, Jul/Set. 2000

CORRÊA, H. L. GIANESI, I. G. N; CAON, M. Planejamento, programação e controle da produção. MRP II/ ERP. São Paulo: Atlas, 2000. .

DAVENPORT, T. H. Ecologia da informação. São Paulo: Futura, 1998.

DRUCKER, P. Desafios para o século XXI. São Paulo: Pioneira, 1999.

FILHO, C. L. Implantação de sistemas ERP. São Paulo: Atlas, 2001.

MAXIMIANO, A. C. A. Introdução à administração. São Paulo: Atlas, 1995.

Paulo: Atlas, 1997.

A. Teoria geral da administração. São

McGEE, J. PRUSAK, L. Gerenciamento estratégico da informação. São Paulo: Campus, 1993.
NANINI, U. O impacto dos sistemas de ERP na competitividade da empresa industrial de médio porte. Dissertação (Mestrado). UNIP, São Paulo, 2001.

O'BRIEN, J. A. Sistemas de informação e as decisões gerenciais na era da internet. São Paulo: Saraiva, 2001.

OLIVEIRA, D. P. R. Sistemas de informações gerenciais. São Paulo: Atlas, 1999.

PRESSMAN, R. S. Engenharia de software. São Paulo: Makron Books, 1995.

REZENDE, D. A; ABREU, A. F. Tecnologia da informação. São Paulo: Atlas, 2000.

ROBBINS, S. P. Administração. Mudanças e perspectivas. São Paulo: Saraiva, 2000.

SHIMIZU, T. Decisão nas organizações. São Paulo: Atlas, 2001.

SILVA, R. S; RODRIGUES, J. E. S. ERP System and Organizational Development. San Diego: Proceedings of Annual Conference, 2001. CD-ROM.

SIMON, H. A. Administrative behavior. A study of decision-making processes in administrative organizations. New York: Free Press, 1997. 